\title{
Article
}

\section{The Role of the Environment in Overweight and Eating Behavior Variability: Insights from a Multivariate Twin Study}

\author{
Moritz Herle ${ }^{1}$, Juan J. Madrid-Valero ${ }^{2}$, José J. Morosoli, ${ }^{3,4}$, Lucía Colodro-Conde ${ }^{3,4}$ and Juan Ordoñana ${ }^{4,5}$ \\ ${ }^{1}$ Department of Biostatistics \& Health Informatics, Institute of Psychiatry, Psychology \& Neuroscience, Kings College London, London, UK, ${ }^{2}$ Department of Health \\ Psychology, University of Alicante, Alicante, Spain, ${ }^{3}$ Department of Genetics and Computational Biology, QIMR Berghofer Medical Research Institute, Brisbane, \\ Queensland, Australia, ${ }^{4}$ Department of Human Anatomy and Psychobiology, University of Murcia, Murcia, Spain and ${ }^{5}$ Murcia Institute for Biomedical Research \\ (IMIB-Arrixaca), Murcia, Spain
}

\begin{abstract}
Research has emphasized the genetic basis of individual differences in body mass index (BMI); however, genetic factors cannot explain the rapid rise of obesity. Eating behaviors have been stipulated to be the behavioral expression of genetic risk in an obesogenic environment. In this study, we decompose variation and covariation between three key eating behaviors and BMI in a sample of 698 participants, consisting of 167 monozygotic, 150 dizygotic complete same-sex female twins and 64 incomplete pairs from a population-based twin registry in the southeast of Spain, The Murcia Twin Registry. Phenotypes were emotional eating, uncontrolled eating and cognitive restraint, measured by the Three Factor Eating Questionnaire and objectively measured BMI. Variation in eating behaviors was driven by nonshared environmental factors (range: 56\%-65\%), whereas shared environmental and genetic factors were secondary. All three eating behaviors were correlated with BMI $(r=.19-.25)$. Nonshared environmental factors explained the covariations (Emotional eating-Uncontrolled eating: $r \mathrm{E}=.54,95 \% \mathrm{CI}[.43, .64]$; BMI-Cognitive restraint: $r \mathrm{E}=.15,95 \% \mathrm{CI}$ $[.01, .28])$. In contrast to BMI, individual differences in eating behaviors are mostly explained by nonshared environmental factors, which also accounted for the phenotypic correlation between eating behaviors and BMI. Due to the sample size, analyses were underpowered to detect contributions of additive genetic or shared environmental factors to variation and covariation of the phenotypes. Although more research is granted, these results support that eating behaviors could be viable intervention targets to help individuals maintain a healthy weight.
\end{abstract}

Keywords: Eating behavior; BMI; twin study; environmental factors

(Received 19 October 2020; accepted 10 December 2020; First Published online 22 January 2021)

Obesity rates remain high, with $28 \%$ of adults classified as having overweight or obesity worldwide (Ng et al., 2014). This is alarming, as overweight and obesity have been associated with health consequences including cardiovascular disease, cancer and overall mortality (Dixon, 2010). However, management of overweight and obesity requires understanding of the intricate interactions of genetic, physiological, behavioral, and social factors that drive body weight (Bray et al., 2018).

In recent years, the genetic basis of obesity has been supported by large-scale genomewide studies, detecting 97 loci associated with body mass index (BMI; Locke et al., 2015). Despite the genetic contribution to obesity, genetic factors cannot account for its rapid rise of over the past decades.

The behavioral susceptibility theory of obesity (Llewellyn \& Wardle, 2015) aims to explain the dual influence of genes and environments by hypothesizing that eating behaviors are the behavioral expression of a genetic susceptibility for obesity in response to an obesogenic food environment. Previous studies

Author for correspondence: Moritz Herle, Email: Moritz.1.herle@kcl.ac.uk

Cite this article: Herle M, Madrid-Valero JJ, Morosoli JJ, Colodro-Conde L, and Ordoñana J. (2021) The Role of the Environment in Overweight and Eating Behavior Variability: Insights from a Multivariate Twin Study. Twin Research and Human Genetics 23: 338-344, https://doi.org/10.1017/thg.2020.90 have highlighted that eating behaviors, such as food-cue responsiveness and emotional overeating, and the tendency to eat in response to negative emotion, such as sadness or loneliness, are associated with body weight and food intake in cross-sectional (Hunot et al., 2016) and longitudinal studies (Syrad et al., 2016). However, less is known about the etiology of eating behaviors. Two recent narrative reviews have summarized previous twin and statistical genetic studies on investigating the heritability of eating behaviors, as well as the genetic link between eating behaviors and BMI (Herle et al., 2020; Silventoinen \& Konttinen, 2020).

Briefly, twin studies have been used to estimate the heritability and environmental influences of eating behaviors in adults, analyzing Western (de Castro \& Lilenfeld, 2005; Keskitalo et al., 2008; Neale et al., 2003; Tholin et al., 2005), Korean (Sung et al., 2010), and Sri Lankan twins (Herle et al., 2019). These estimates vary widely across studies: $9 \%-72 \%$ for emotional eating, $45 \%$ $-77 \%$ for responsiveness to external food cues and $0 \%-69 \%$ for restraint or fasting behaviors (Herle et al., 2019; Keskitalo et al., 2008; Neale et al., 2003; Sung et al., 2010; Tholin et al., 2005). These heterogeneous results might be explained by differences between the studied populations. Previous twin studies included individuals with a large age range (late adolescence to older adulthood), and were often drawn from public health registers, coming

(c) The Author(s), 2021. Published by Cambridge University Press. This is an Open Access article, distributed under the terms of the Creative Commons Attribution licence (http://creativecommons.org/licenses/by/4.0/), which permits unrestricted re-use, distribution, and reproduction in any medium, provided the original work is properly cited. 
from markedly different regions and socio-economic backgrounds within each country. This is important, because in the case of BMI, genetic factors have been found to contribute more to the differences in BMI in twins of highly educated parents, whereas environmental factors were found to be more important in families of parents with limited education (Lajunen et al., 2012), which is congruent with recent evidence for gene-environment interactions for BMI (Komulainen et al., 2018).

In the current study, we aim to add to the current body of literature and provide novel insights by studying a more homogenous sample of women in their middle adulthood from the southeast of Spain. We explore the contribution of genetic and environmental factors to the relationship between BMI and eating behaviors in a specific region of Mediterranean country, in contrast to previous studies analyzing data from countrywide twin registers in northern Europe.

\section{Methods}

\section{Participants}

Data came from the Murcia Twin Registry (MTR), a populationbased twin registry of adult multiples born between 1940 and 1976 in the region of Murcia, Southeast of Spain. Information regarding the MTR characteristics and recruitment procedures can be found elsewhere (Ordonana et al., 2019). MTR participants are representative of the general population of the corresponding ages in terms of demographic and health data. A comparison with reference surveys at a regional and national level showed that MTR participants presented comparable prevalence in chronic conditions and other health variables to the general population of Murcia and Spain (Ordonana et al., 2018). The sample for this study was composed of 698 participants, consisting of 167 monozygotic (MZ), 150 dizygotic (DZ) same-sex female twins and 64 incomplete pairs) born between 1946 and 1966, who participated in the data collection in 2009, had objectively measured BMI data available and answered items in the questionnaire on eating behaviors (age at data collection: mean $=53.13, S D=7.55$, range $43-69$ ). All registry and data-collection procedures involved in this study were approved by the Murcia University Ethics Committee, and informed consent was obtained from all twins.

\section{Measures}

Eating behaviors were measured with the Spanish version of the Three Factor Eating Behavior Questionnaire - R18 (TFEQ-R; JaureguiLobera et al., 2014). The questionnaire consists of three subscales: Emotional eating, which describes the tendency to eat when faced with negative emotions (three items; e.g. 'When I feel lonely, I console myself with eating'), uncontrolled eating indicating a lack of control over food intake (nine items; e.g. 'Sometimes when I start eating, I just can't seem to stop'), and cognitive restraint, the tendency to restrict food intake in order to control weight (six items; e.g. 'I consciously hold back at meals in order not to gain weight'). Mean scores were calculated for Emotional Eating, Uncontrolled Eating and Cognitive restraint. Scores were regressed on age at measurement as this is shared completely within twin pairs and potentially inflate twin-pair similarity (McGue \& Bouchard, 1984). The three subscales had good internal consistency in this sample: Emotional eating, McDonald's omega $=.77$ (95\% CI $[.61, .86])$; Uncontrolled eating, McDonald's omega $=.9$ (95\% CI: .82, .94) and Cognitive restraint, McDonald's omega $=.86$ (95\% CI: .80, .92). Participants were only included if they had data on all items needed to calculate the subscales, leading to loss of participants; emotional eating 15 participants excluded, cognitive restraint 23 participants excluded and uncontrolled eating 28 participants excluded. The different $N$ s for the different subscales are reported in Table 1.

A blinded research assistant collected anthropometric measurements during data collection interviews. Body weight was measured using a TANITA BC-240 MA (Tanita Corporaton of America, USA) and height using a portable stadiometer. BMI was calculated by dividing the individuals' body weight in kilograms by the square of their height in meters.

Analyses. The twin design is based on the comparison of $\mathrm{MZ}$ and dizygotic DZ twins. MZ twins share $100 \%$ of their DNA, whereas DZ twins share on average about half of their segregating genes. Importantly, as both types of twins are exposed to very similar environments, such as intrauterine exposures and aspects of parental upbringing, difference in the correlation between $\mathrm{MZ}$ and $\mathrm{DZ}$ twin pairs is assumed to reflect genetic differences (Boomsma et al., 2002). These genetic components can be divided into additive (A; i.e. summed allelic effects across multiple genes) and nonadditive (D; i.e. genetic dominance, possibly including epistasis) factors, whereas the environmental factors can be divided into shared (C; i.e. common/family environment) and individual or unique (E; i.e. idiosyncratic experiences; this component also includes measurement error) environmental factors. It is not possible to estimate $\mathrm{C}$ and $\mathrm{D}$ simultaneously in a classical twin model, and the choice of modeling $\mathrm{C}$ or D depends on the pattern of MZ and DZ correlations. Usually, $\mathrm{C}$ is estimated if the DZ twin correlation is more than half of the MZ twin correlation, and $\mathrm{D}$ is estimated if the $\mathrm{DZ}$ twin correlation is less than half of the MZ correlation (Rijsdijk \& Sham, 2002). Overall, a greater phenotypic similarity in MZ twin pairs compared with $\mathrm{DZ}$ twin pairs is attributed to genetic influences (A or D components), under the assumption that both $\mathrm{MZ}$ and $\mathrm{DZ}$ twins are exposed to equal shared environments.

Maximum likelihood structural equation modeling is used to fit the models and provide parameter estimates with $95 \%$ confidence intervals. First, a saturated model with no parameter constraints is fitted. Assumptions of the twin design are also tested, including the homogeneity of the means and variances of first and second born twins, and across zygosity groups. Followed by the full model with the $\mathrm{A}, \mathrm{C}$ and $\mathrm{E}$ components, nested models that constrain $\mathrm{A}$ and $\mathrm{C}$ to be zero are tested. Model fit is compared using likelihood ratio test (Rijsdijk \& Sham, 2002) and the Akaike Information Criterion (AIC; Posada \& Buckley, 2004). Further details of the twin design, including testing assumptions, can be found elsewhere (Posthuma et al., 2003).

As an extension to this concept, multivariate twin models decompose in addition the covariance between multiple phenotypes following the same principles. A multivariate ACE model provides etiological correlations (denoted $r \mathrm{~A}, r \mathrm{C}$ and $r \mathrm{E}$, ranging from -1 to 1 ), which indicate the extent to which the $A, C$ and $\mathrm{E}$ factors that explain individual differences in one phenotype also affect the other. In this study, a multivariate ACE model including the eating behavior variables and BMI was fit. Furthermore, the derived etiological correlations can be used to decompose the phenotypic correlation between the two phenotypes: by dividing the etiological correlations by the phenotypic correlation, the proportion of the correlation that is due to A, C and E can be calculated (Rijsdijk \& Sham, 2002).

All analyses were conducted in $\mathrm{R}$ using the OpenMx package (Boker et al., 2011). To note, our study (with 175 complete MZ pairs and 170 complete DZ pairs) is well powered (90\%) to detect 
Table 1. Descriptive statistics for analyses sample (total $N=698$ )

\begin{tabular}{lc}
\hline Zygosity & $N(\%)$ or Mean $(S D)$ \\
\hline Monozygotic & 359 \\
\hline Dizygotic & 359 \\
\hline Age & $53.13(7.55)$ \\
\hline Education & $2(<1)$ \\
\hline Illiterate & $72(10)$ \\
\hline No education (reading \& writing) & $239(34)$ \\
\hline Primary school & $187(27)$ \\
\hline Secondary school & $65(9)$ \\
\hline Vocational training & $38(5)$ \\
\hline A-levels & $60(13)$ \\
\hline University degree & $17(2)$ \\
\hline Missing & $27.58(5.06)$ \\
\hline Body mass index, $n=694$ & $228(32)$ \\
\hline Healthy weight, $18.5-25$ & $5(1)$ \\
\hline Underweight, $<18$ & $264(38)$ \\
\hline Overweight, $25-30$ & $197(28)$ \\
\hline Obese, $>30$ & $4(1)$ \\
\hline Missing & $1.60(.80)$ \\
\hline Emotional eating, $N=683$ & $2.24(.94)$ \\
\hline Cognitive restraint, $N=675$ & $1.49(.56)$ \\
\hline Uncontrolled eating, $N=670$ & \\
\hline & \\
\hline & \\
\hline
\end{tabular}

A in a model where A explains 50\% of the variance and E explains the remainder - which is the average value reported in metaanalysis of behavioral traits (Polderman et al., 2015). However, our study is not well powered to detect $\mathrm{C}$ in a model where both $\mathrm{A}$ and $\mathrm{C}$ have a significant role (for a model where A explains $30 \%$ and $\mathrm{C}$ explains $20 \%$, the power to detect $\mathrm{A}$ is $60 \%$ and the power to detect $\mathrm{C}$ is 40\%; Visscher, 2004; Visscher et al., 2008).

The analytical code is available on https:/github.com/ MoritzHerle/The-role-of-the-environment-in-overweight-andeating-behavior-variability.

\section{Results}

Descriptive statistics can be found in Table 1. Two-thirds of the participants had either overweight or obesity.

\section{Phenotypic Correlations}

All phenotypes were positively correlated, including the correlations between BMI and the eating behaviors, which were small but significant. The highest correlation was found between emotional eating and uncontrolled eating; see Table 2 for all correlations.

Intraclass correlations indicate the similarity of one twin with their co-twin and are compared across MZ and DZ twin pairs. $\mathrm{MZ}$ twin intraclass correlations were greater (but not more than twice) than DZ intraclass correlations for Emotional Eating and BMI, indicating that a model including additive genetic and common environment effects might be the most suitable for the data, instead of assuming additive and dominant genetic effects (Rijsdijk \& Sham, 2002). The twin intraclass correlations for Cognitive Restraint and Uncontrolled Eating suggest a negligible
Table 2. Phenotypic correlations ( $95 \%$ confidence intervals) of eating behaviors and body mass index in the Murcia twin register $(N=698)$

\begin{tabular}{|c|c|c|c|c|}
\hline & $\mathrm{EE}$ & $\mathrm{CR}$ & UE & BMI \\
\hline $\mathrm{EE}$ & 1 & & & \\
\hline CR & $.16(.08, .24)$ & 1 & & \\
\hline UE & $.59(.53, .64)$ & $.12(.04, .20)$ & 1 & \\
\hline BMI & $.19(.11, .27)$ & $.25(.17, .32)$ & $.20(.12, .28)$ & 1 \\
\hline
\end{tabular}

Note: EE, Emotional eating; CR, Cognitive restraint; UE, Uncontrolled eating; BMI, Body mass index.

Table 3. Intraclass correlations ( $95 \%$ confidence intervals) of eating behaviors and body mass index for monozygotic (MZ) and dizygotic (DZ) twin pairs (167 MZ and $150 \mathrm{DZ}$ complete pairs)

\begin{tabular}{lcc}
\hline & $M Z(n=175$ pairs $)$ & $D Z(n=170$ pairs $)$ \\
\hline EE & $.35(.21, .48)$ & $.22(.05, .37)$ \\
\hline CR & $.32(.17, .45)$ & $.34(.18, .47)$ \\
\hline UE & $.38(.24, .50)$ & $.36(.20, .50)$ \\
\hline BMI & $.66(.56, .73)$ & $.39(.23, .52)$ \\
\hline
\end{tabular}

Note: MZ, Monozygotic twins; DZ, Dizygotic twins; EE, Emotional eating; CR, Cognitive restraint; UE, Uncontrolled eating; BMI: Body mass index.

influence of genetic additive genetic factors. See Table 3 for all intraclass correlations.

\section{Decomposition of Variance}

Means and variances of all variables could be equated across twin order and zygosity groups, suggesting that assumptions of the twin design were met. A multivariate ACE model (including all parameters - A, C and $\mathrm{E}-$ for BMI and all three eating behaviors, as well as $r \mathrm{~A}, r \mathrm{C}$ and $r \mathrm{E}$ between them) with means and variance equated within first- and second-born twins and across zygosity groups fit the data well as the comparison with the saturated model indicated no significant drop in model fit between the two models $\left(\chi^{2}=63.130, p=.18\right)$. In line with likelihood ratio test, AIC also favored the more parsimonious multivariate ACE model over the saturated model $\left(\mathrm{AIC}_{\mathrm{ACE}}\right.$ : 12203.6, vs. $\left.\mathrm{AIC}_{\mathrm{FULL}}: 12248.5\right)$. Full fit statistics for the saturated and multivariate ACE model are shown in Table 4.

Table 5 shows the parameter estimates for A, C and E (and 95\% $\mathrm{CI}$ ), indicating the relative importance of genetic, shared environmental and nonshared environmental influences (including measurement error) on variation in BMI and the three eating behaviors. Variation in all eating behaviors was mostly explained by nonshared environmental factors and measurement error (range from .56 to .64). The lack of power did not allow the distinction between genetic and shared environmental components and only cognitive restraint showed that shared environmental factors accounted for about one quarter of the variance $(C=.26$; $95 \%$ CI $[.04, .40])$. In contrast, variation in BMI was similarly explained by genetic effects $(\mathrm{A}=.43 ; 95 \% \mathrm{CI}[.13, .69])$ and nonshared environmental effects $(\mathrm{E}=.36 ; 95 \% \mathrm{CI}[.29, .45])$.

\section{Decomposition of Covariance}

As shown in Table 2, all variables were significantly positively correlated with each other. Most of the etiological correlations $(r \mathrm{~A}, r \mathrm{C}$ 
Table 4. Fit statistics for twin model fitting, Murcia twin registry (167 monozygotic and 150 dizygotic complete pairs)

\begin{tabular}{lcccccc}
\hline Model & EP & $d f$ & $-2 \mathrm{LL}$ & AIC & $\Delta \chi^{2}(d f)$ & $p$ value \\
\hline Full Saturated & 88 & 2634 & 17516.51 & 12248.51 & & \\
\hline ACE & 34 & 2692 & 17579.64 & 12203.6 & $63.130(54)$ & .18 \\
\hline
\end{tabular}

Note: A, Additive genetic factors, $C$, shared environmental factors, E, nonshared environmental factors, EP, estimated parameters; $d f$, degrees of freedom; $-2 \mathrm{LL},-2$ loglikelihood; AIC, Akaike's information criterion, $\Delta \chi^{2}$, differenced in chi-square.

Table 5. Results from multivariate ACE model, univariate variance components (95\% confidence intervals; $167 \mathrm{MZ}, 150 \mathrm{DZ}$ complete pairs)

\begin{tabular}{cccc}
\hline & $\mathrm{A}$ & $\mathrm{C}$ & $\mathrm{E}$ \\
\hline $\mathrm{EE}$ & $.26(.00, .47)$ & $.10(.00, .35)$ & $.64(.52, .78)$ \\
\hline $\mathrm{CR}$ & $.09(.00, .34)$ & $.26(.04, .40)$ & $.65(.55, .76)$ \\
\hline UE & $.22(.00, .53)$ & $.22(.00, .45)$ & $.56(.45, .70)$ \\
\hline BMI & $.43(.13, .69)$ & $.21(.00, .47)$ & $.36(.29, .45)$ \\
\hline
\end{tabular}

Note: A, Additive genetic factors, $C$, shared environmental factors, $E$, nonshared environmental factors, $\mathrm{EE}$, Emotional eating; $\mathrm{CR}$, Cognitive restraint; UE, Uncontrolled eating; BMI, Body mass index.

and $r \mathrm{E}$ ) were nonsignificant and showed large confidence intervals, likely due to low statistical power (see Table 6). Uncontrolled Eating and Emotional Eating were found to be influenced, in part, by similar nonshared environmental factors $(r \mathrm{E}=.54,95 \% \mathrm{CI}[.43$, .64]). Furthermore, results indicated that cognitive restraint and BMI had nonshared environmental factors in common $(r \mathrm{E}=.15,95 \% \mathrm{CI}[.01, .28])$, as well as Uncontrolled Eating and $\mathrm{BMI}(r \mathrm{E}=.15,95 \% \mathrm{CI}[.00, .29])$. Regarding the percentage of phenotypic correlations explained by genetic and environmental factors, $92 \%$ of the Emotional Eating-Uncontrolled Eating correlation was due to nonshared environmental factors; $60 \%$ of the Cognitive Restraint-BMI was accounted by nonshared environmental factors and $75 \%$ of the Uncontrolled Eating-BMI phenotypic correlation was attributed to nonshared environmental factors. Contributions of genetic and shared environmental factors could not be calculated due to the nonsignificant etiological correlations. Results are illustrated in Figure 1.

\section{Discussion}

In summary, the present study aimed to explore the sources of variance and covariance of BMI and eating behaviors in a sample of adult women living in Murcia (Spain). The influence of additive genetic factors and common environment could not be disentangled due to lack of power. We estimated that unique environmental factors and measurement error explained more than half of the variance of Emotional Eating, Uncontrolled Eating and Cognitive Restriction. Unique environmental experiences were shared to a small extent between two of the eating behaviors, Uncontrolled Eating and Cognitive Restriction, and BMI, supporting the potential value of environmental factors as viable intervention targets in older cohorts with similar characteristics.

Our findings are partially in line with previous twin studies of adult eating behaviors, confirming the importance of environmental factors in those behaviors (de Castro \& Lilenfeld, 2005; Herle et al., 2019; Keskitalo et al., 2008; Neale et al., 2003; Sung et al., 2010; Tholin et al., 2005). Specifically, our results mirror findings from an early twin study that has similar characteristics to ours.
Table 6. Results from multivariate ACE model, etiological correlations $r \mathrm{~A}, r \mathrm{C}$ and $r$ E (95\% confidence intervals; $167 \mathrm{MZ}, 150 \mathrm{DZ}$ complete pairs)

\begin{tabular}{|c|c|c|c|c|}
\hline \multicolumn{5}{|c|}{ Additive genetic factors $(r \mathrm{~A})$} \\
\hline & $\mathrm{EE}$ & $\mathrm{CR}$ & UE & $\mathrm{BMI}$ \\
\hline $\mathrm{EE}$ & 1 & & & \\
\hline CR & $.47(-1,1)$ & 1 & & \\
\hline UE & $.49(-1,1)$ & $-.06(-1,1)$ & 1 & \\
\hline BMI & $.27(-1,1)$ & $.78(-.1,1)$ & $.39(-1,1)$ & 1 \\
\hline \multicolumn{5}{|c|}{ Shared environmental factors $(r \mathrm{C})$} \\
\hline & $\mathrm{EE}$ & $\mathrm{CR}$ & UE & $\mathrm{BMI}$ \\
\hline $\mathrm{EE}$ & 1 & & & \\
\hline $\mathrm{CR}$ & $.13(-1,1)$ & 1 & & \\
\hline UE & $.94(-1,1)$ & $.37(-1,1)$ & 1 & \\
\hline BMI & $.28(-1.1)$ & $-.09(-1,1)$ & $.00(-1,1)$ & 1 \\
\hline \multicolumn{5}{|c|}{ Nonshared environmental (factors $r \mathrm{E}$ ) } \\
\hline & $\mathrm{EE}$ & $\mathrm{CR}$ & UE & BMI \\
\hline $\mathrm{EE}$ & 1 & & & \\
\hline CR & $.07(-.06, .21)$ & 1 & & \\
\hline UE & $.54(.43, .64)$ & $.03(-.10, .16)$ & 1 & \\
\hline BMI & $.11(-.04, .25)$ & $.15(.01, .28)$ & $.15(.00, .29)$ & 1 \\
\hline
\end{tabular}

Note: EE, Emotional eating; CR, Cognitive restraint; UE, Uncontrolled eating; BMI, Body mass index.

Their results indicated how nonshared environmental factors explain most of variation in eating behaviors in a small sample of adult female twin pairs (Neale et al., 2003). However, despite the twin correlations suggesting that genetic factors play a role at least in Emotional Eating, we could not estimate the proportion of variance due to genetic factors and common environment in most of our phenotypes due to lack of power. Individual differences in Cognitive Restraint are partially explained by shared environmental factors in our sample. Previous research has suggested that siblings and parents act as role models and inspire dietary behaviors, such as Cognitive Restraint (Coomber \& King, 2008). This might imply that twins encourage each other to lose weight and constrain their food intake, resulting in higher estimates of shared environmental effects. This highlights the potential of including close family members or friends, when designing interventions aimed at weight management. Familywide interventions are common practice for children and adolescence (Berge \& Everts, 2011) but might be important for older adults, especially when living in close-knit communities. For childhood and adolescent obesity, previous research has highlighted the important influence of siblings (Park \& Cormier, 2018) and close friends (Salvy et al., 2017), but less is known about the influence of siblings on dietary behaviors in middle and late adulthood This rationale could extend to group interventions, which harness the dynamic interactions between group members to facilitate behavior change (Paul-Ebhohimhen \& Avenell, 2009).

The heritability of BMI was moderate in our sample, in line with previous work showing that genetic factors on BMI tend to increase during childhood (Haworth et al., 2008) and into adulthood (Min et al., 2013), but then decrease again in older adulthood (Nan et al., 2012). Despite the established evidence of the strong genetic etiology of obesity (Locke et al., 2015; Min et al., 2013), 


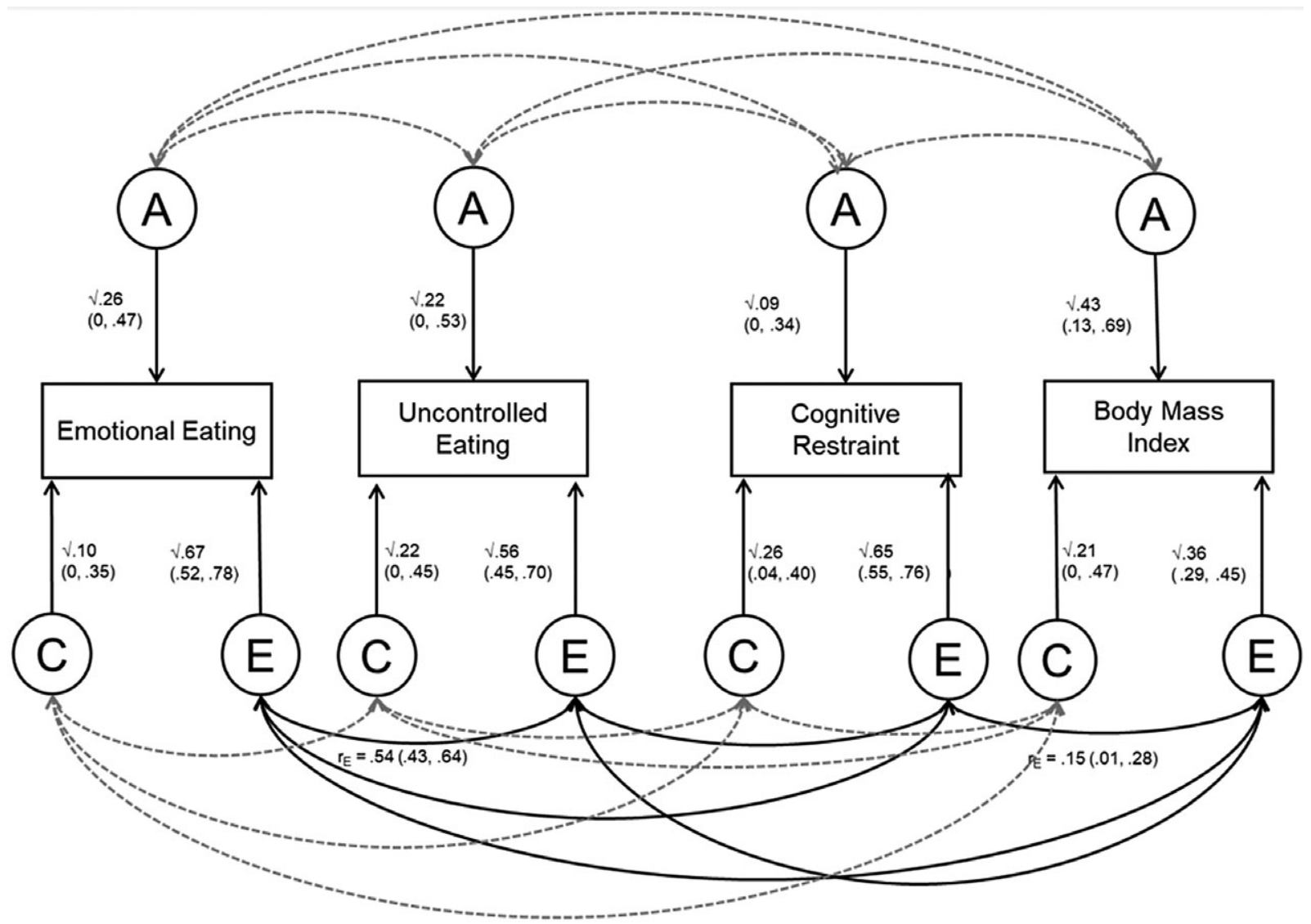

Fig. 1. Path diagram illustrating the results from the multivariate twin model decomposing variances and covariances into additive genetics (A), shared environment (C) and nonshared environmental (E) latent factors. Dotted lines indicate nonsignificant paths (167 monozygotic and 150 dizygotic complete pairs).

our study highlights how, in this sample, environmental factors are important in explaining individual differences. This finding is a key as environmental interventions remain the most common strategies to lose weight.

Regarding the relationship between eating behaviors, we report a moderate phenotypic correlation between Emotional Eating and Uncontrolled Eating. These behaviors are potential intervention targets to help people to reach and maintain healthy weight. Weight loss interventions - targeting eating behaviors specifically — are currently in development and have shown some promise (Hunot et al., 2016). The underlying etiology of the covariance of Emotional Eating and Uncontrolled Eating show the importance of unique environmental factors $\left(r_{\mathrm{E}}=.54\right.$; CI 95\% $\left.[.43, .64]\right)$. This might be interpreted as environmental triggers associated with emotional eating are also associated with uncontrolled eating. This is in line with previous research indicating that negative emotions (which are likely to be influenced by environmental factors) trigger overeating and binge-eating behavior (Leehr et al., 2015).

Keskitalo et al. reported similar findings in a sample of adults aged 17 to 82 years old living in the UK and Finland. However, our study was not well powered to estimate shared genetic etiology between BMI and any of the other eating behaviors, and confidence for all $r_{\mathrm{A}}$ estimates crossed zero. We report evidence of a small unique environment correlation between some eating behaviors and BMI. In addition to BMI, eating behaviors are also linked to disordered eating behaviors and cognitions, commonly observed in patients with eating disorders, and these relationships may vary across the lifespan. In this context, studies focusing on adolescence have suggested that hormonal changes in puberty might have a significant impact on the genetic and environmental contributions to individual differences in eating behavior related phenotypes such as weight and shape concerns (O'Connor et al., 2020) as well as core symptoms of eating disorders such as binge eating (Klump et al., 2017). Similarly, previous studies have reported that the polygenic risk score for BMI was associated with disordered eating behaviors and emotional eating in adolescence (Abdulkadir et al., 2020; Nagata et al., 2019; Robinson et al., 2020).

\section{Strengths and Limitations}

The main limitation of our study is the reduced sample size, resulting in large confidence intervals, precluding a straightforward interpretation of the decomposition of the variance and covariance of the phenotypes. Our sample included only women. Henceforth we were not able to investigate etiological differences between men and women. Previous twin studies have discussed these differences; for example, a higher heritability of emotional eating in women (Herle et al., 2019). Furthermore, eating behaviors were self-reported, which might have introduced reporting bias. However, the Three Factor Eating Questionnaire is a widely used tool and has been validated against measures of food intake (de Lauzon et al., 2004) and correlates with $\mathrm{BMI}$ in the expected direction in this sample.

As with all other twin research, this study needs to conform to the assumptions underlying the twin method. 'The Equal Environment Assumption' (EEA) states that environmental exposures influencing the variation of a trait are unrelated to the 
zygosity of the twin pairs - that is, that MZs and DZs share their environments to the same extent. A violation of the EEA could lead to an overestimation of the genetic contribution to variation. However, previous studies have confirmed the validity of the EEA in twin studies in general, as well as specifically in twin research studying eating behaviors (Klump et al., 2000). For this twin registry specifically, previous research has found no violation of EEA in other behaviors and health indicators (Sánchez-Romera, 2013). In addition, some of the phenotypic correlations were small $(<.2)$, but significant; Cognitive Restraint - Emotional Eating, Cognitive Restraint - Uncontrolled Eating and Emotional Eating - BMI. Decomposing small phenotypic correlations into their etiological components might be seen of limited value, as the results produced only describe a potentially negligible overlap between two variables.

The main strengths are the characteristics of the Murcia Twin Registry and the distinctiveness of the sample. Female participants in this study are in their perimenopausal years. They had on average high body weight, and two thirds of the sample had either overweight or obesity. Instead of over-representing wealthy, healthy or highly educated individuals, this cohort is population based and representative of the Region of Murcia and Spain, with homogeneous and well-known geographic and cultural characteristics. On the other hand, due to this geographically specific sample, the results are not generalizable to the wider population. Although larger sample sizes are required to distinguish the sources of variance and covariance due to additive genetic factors and common environmental factors between the eating behaviors and BMI, this study gives insight into the relative influence of environmental factors in a sample considered to be at higher risk of developing overweight and obesity.

\section{Conclusions}

Findings of this study suggest that eating behaviors are positively associated with BMI at a phenotypic level. Although limited in statistical power to identify other factors, nonshared environmental factors explained most of the individual differences in each of the phenotypes and showed a significant role in some of the associations between phenotypes in our sample. Eating behaviors might be promising intervention targets, supporting individuals in maintaining healthy weight. Finally, twin studies are a powerful tool to study the influence of environmental factors when the trait of interest (BMI in our case) is clearly influenced by genetic factors.

Acknowledgments. We would like to thank the members of the Murcia Twin Registry for their participation.

Financial support. The Murcia Twin Registry is being funded by Seneca Foundation - Regional Agency for Science and Technology, Murcia, Spain (grants 03082/PHCS/05, 08633/PHCS/08, 15302/PHCS/10 and 19479/PI/14) and the Spanish Ministry of Science and Innovation (PSI2009-11560 and PSI2014-56680-R). Dr Herle is funded by fellowship from the Medical Research Council UK (MR/T027843/1). A/Prof Colodro-Conde is supported by a QIMR Berghofer fellowship.

Conflict of interest. None.

\section{References}

Abdulkadir, M., Herle, M., De Stavola, B. L., Hubel, C., Santos Ferreira, D. L., Loos, R. J. F., ... Micali, N. (2020). Polygenic score for body mass index is associated with disordered eating in a general population cohort. Journal of Clinical Medicine, 9, 1187.
Berge, J. M., \& Everts, J. C. (2011). Family-Based interventions targeting childhood obesity: A meta-analysis. Childhood Obesity, 7, 110-121.

Boker, S., Neale, M., Maes, H., Wilde, M., Spiegel, M., Brick, T., . . Fox, J. (2011). OpenMx: An open source extended structural equation modeling framework. Psychometrika, 76, 306-317.

Boomsma, D., Busjahn, A., \& Peltonen, L. (2002). Classical twin studies and beyond. Nature Reviews Genetics, 3, 872-882.

Bray, G. A., Heisel, W. E., Afshin, A., Jensen, M. D., Dietz, W. H., Long, M., ... Inge, T. H. (2018). The science of obesity management: An Endocrine Society Scientific Statement. Endocrine Reviews, 39, 79-132.

Coomber, K., \& King, R. M. (2008). The role of sisters in body image dissatisfaction and disordered eating. Sex Roles, 59, 81-93.

de Castro, J. M., \& Lilenfeld, L. R. (2005). Influence of heredity on dietary restraint, disinhibition, and perceived hunger in humans. Nutrition, 21, 446-455.

de Lauzon, B., Romon, M., Deschamps, V., Lafay, L., Borys, J. M., Karlsson, J., ... Grp, F. S. (2004). The three-factor eating questionnaire-R18 is able to distinguish among different eating patterns in a general population. Journal of Nutrition, 134, 2372-2380.

Dixon, J. B. (2010). The effect of obesity on health outcomes. Molecular and Cellular Endocrinology, 316, 104-108.

Haworth, C. M. A., Carnell, S., Meaburn, E. L., Davis, O. S. P., Plomin, R., \& Wardle, J. (2008). Increasing heritability of BMI and stronger associations with the FTO gene over childhood. Obesity, 16, 2663-2668.

Herle, M., Smith, A. D., Kininmonth, A., \& Llewellyn, C. (2020). The role of eating behaviours in genetic susceptibility to obesity. Current Obesity Reports, 9, 512-521.

Herle, M. P., Kan, C., Jayaweera, K., Adikari, A., Siribaddana, S., Zavos, H. M. S., ... Rijsdijk, F. (2019). The association between emotional eating and depressive symptoms: A population-based twin study in Sri Lanka. Global Health Epidemiology and Genomics, 4, e4.

Hunot, C., Fildes, A., Croker, H., Llewellyn, C. H., Wardle, J., \& Beeken, R. J. (2016). Appetitive traits and relationships with BMI in adults: Development of the Adult Eating Behaviour Questionnaire. Appetite, 105, 356-363.

Jauregui-Lobera, I., Garcia-Cruz, P., Carbonero-Carreno, R., Magallares, A., \& Ruiz-Prieto, I. (2014). Psychometric properties of Spanish version of the Three-Factor Eating Questionnaire-R18 (Tfeq-Sp) and its relationship with some eating- and body image-related variables. Nutrients, 6(12), 5619-5635.

Keskitalo, K., Tuorila, H., Spector, T. D., Cherkas, L. F., Knaapila, A., Kaprio, J., ... Perola, M. (2008). The Three-Factor Eating Questionnaire, body mass index, and responses to sweet and salty fatty foods: A twin study of genetic and environmental associations. American Journal of Clinical Nutrition, 88, 263-271.

Klump, K. L., Culbert, K. M., O'Connor, S., Fowler, N., \& Burt, S. A. (2017). The significant effects of puberty on the genetic diathesis of binge eating in girls. International Journal of Eating Disorders, 50, 984-989.

Klump, K. L., Holly, A., Iacono, W. G., McGue, M., \& Willson, L. E. (2000). Physical similarity and twin resemblance for eating attitudes and behaviors: A test of the equal environments assumption. Behavior Genetics, 30, 51-58.

Komulainen, K., Pulkki-Raback, L., Jokela, M., Lyytikainen, L. P., Pitkanen, N., Laitinen, T., .. Keltikangas-Jarvinen, L. (2018). Education as a moderator of genetic risk for higher body mass index: Prospective cohort study from childhood to adulthood. International Journal of Obesity, 42, 866-871.

Lajunen, H. R., Kaprio, J., Rose, R. J., Pulkkinen, L., \& Silventoinen, K. (2012). Genetic and environmental influences on BMI from late childhood to adolescence are modified by parental education. Obesity (Silver Spring), 20, 583-589.

Leehr, E. J., Krohmer, K., Schag, K., Dresler, T., Zipfel, S., \& Giel, K. E. (2015). Emotion regulation model in binge eating disorder and obesity A systematic review. Neuroscience and Biobehavioral Reviews, 49, 125-134.

Llewellyn, C., \& Wardle, J. (2015). Behavioral susceptibility to obesity: GeneEnvironment interplay in the development of weight. Physiology \& Behavior, 152(Pt B), 494-501.

Locke, A. E., Kahali, B., Berndt, S. I., Justice, A. E., Pers, T. H., Felix, R., . . Speliotes, E. K. (2015). Genetic studies of body mass index yield new insights for obesity biology. Nature, 518, 197206.

McGue, M., \& Bouchard, T. J. (1984). Adjustment of twin data for the effects of age and sex. Behavior Genetics, 14, 325-343. 
Min, J., Chiu, D. T., \& Wang, Y. (2013). Variation in the heritability of body mass index based on diverse twin studies: A systematic review. Obesity Reviews, 14, 871-882.

Nagata, J. M., Braudt, D. B., Domingue, B. W., Bibbins-Domingo, K., Garber, A. K., Griffiths, S., \& Murray, S. B. (2019). Genetic risk, body mass index, and weight control behaviors: Unlocking the triad. International Journal of Eating Disorders, 52, 825-833.

Nan, C., Guo, B., Warner, C., Fowler, T., Barrett, T., Boomsma, D., .. . Zeegers, M. (2012). Heritability of body mass index in pre-adolescence, young adulthood and late adulthood. European Journal of Epidemiology, 27, 247-253.

Neale, B. M., Mazzeo, S. E., \& Bulik, C. M. (2003). A twin study of dietary restraint, disinhibition and hunger: An examination of the Eating Inventory (Three Factor Eating Questionnaire). Twin Research, 6, 471-478.

Ng, M., Fleming, T., Robinson, M., Thomson, B., Graetz, N., Margono, C., ... Gakidou, E. (2014). Global, regional, and national prevalence of overweight and obesity in children and adults during 1980-2013: A systematic analysis for the Global Burden of Disease Study 2013. Lancet, 384, 766-781.

O’Connor, S. M., Culbert, K. M., Mayhall, L. A., Burt, S. A., \& Klump, K. L. (2020). Differences in genetic and environmental influences on body weight and shape concerns across pubertal development in females. Journal of Psychiatric Research, 121, 39-46.

Ordonana, J. R., Carrillo, E., Colodro-Conde, L., Garcia-Palomo, F. J., Gonzalez-Javier, F., Madrid-Valero, J. J., ... Sanchez-Romera, J. F. (2019). An update of twin research in Spain: The Murcia Twin Registry. Twin Research and Human Genetics, 22, 667-671.

Ordonana, J. R., Sanchez Romera, J. F., Colodro-Conde, L., Carrillo, E., Gonzalez-Javier, F., Madrid-Valero, J. J., ... Martinez-Selva, J. M. (2018). The Murcia Twin Registry. A resource for research on health-related behaviour. Gaceta Sanitaria, 32, 92-95.

Park, S. H., \& Cormier, E. (2018). Influence of siblings on child health behaviors and obesity: A systematic review. Journal of Child and Family Studies, 27, 2069-2081.

Paul-Ebhohimhen, V., \& Avenell, A. (2009). A systematic review of the effectiveness of group versus individual treatments for adult obesity. Obesity Facts, 2, 17-24.

Polderman, T. J., Benyamin, B., de Leeuw, C. A., Sullivan, P. F., van Bochoven, A., Visscher, P. M., \& Posthuma, D. (2015). Meta-Analysis of the heritability of human traits based on fifty years of twin studies. Nature Genetics, 47, 702-709.

Posada, D., \& Buckley, T. R. (2004). Model selection and model averaging in phylogenetics: Advantages of Akaike information criterion and Bayesian approaches over likelihood ratio tests. Systematic Biology, 53, 793-808.

Posthuma, D., Beem, A. L., de Geus, E. J. C., van Baal, G. C. M., von Hjelmborg, J. B., Lachine, I., \& Boomsma, D. I. (2003). Theory and practice in quantitative genetics. Twin Research, 6, 361-376.

Rijsdijk, F. V., \& Sham, P. C. (2002). Analytic approaches to twin data using structural equation models. Briefings in Bioinformatics, 3, 119-133.

Robinson, L., Zhang, Z., Jia, T., Bobou, M., Roach, A., Campbell, I., ... Consortium, I. (2020). Association of genetic and phenotypic assessments with onset of disordered eating behaviors and comorbid mental health problems among adolescents. JAMA Network Open, 3, e2026874.

Salvy, S. J., Feda, D. M., Epstein, L. H., \& Roemmich, J. N. (2017). Friends and social contexts as unshared environments: A discordant sibling analysis of obesity- and health-related behaviors in young adolescents. International Journal of Obesity, 41, 569-575.

Sánchez-Romera, J. F. (2013). Registros de gemelos: utilidades, organización y supuestosclave. Registro de Gemelos de Murcia (Genètica general). Murcia, Spain: Universidad de Murcia.

Silventoinen, K., \& Konttinen, H. (2020). Obesity and eating behavior from the perspective of twin and genetic research. Neuroscience \& Biobehavioral Reviews, 109, 150-165.

Sung, J., Lee, K., Song, Y. M., Lee, M. K., \& Lee, D. H. (2010). Heritability of eating behavior assessed using the DEBQ (Dutch Eating Behavior Questionnaire) and weight-related traits: The Healthy Twin Study. Obesity, 18, 1000-1005.

Syrad, H., Johnson, L., Wardle, J., \& Llewellyn, C. H. (2016). Appetitive traits and food intake patterns in early life. American Journal of Clinical Nutrition, 103, 231-235.

Tholin, S., Rasmussen, F., Tynelius, P., \& Karlsson, J. (2005). Genetic and environmental influences on eating behavior: The Swedish young male twins study. American Journal of Clinical Nutrition, 81, 564-569.

Visscher, P. M. (2004). Power of the classical twin design revisited. Twin Research, 7, 505-512.

Visscher, P. M., Gordon, S., \& Neale, M. C. (2008). Power of the classical twin design revisited: II detection of common environmental variance. Twin Research and Human Genetics, 11, 48-54. 